\title{
Ultrasound-assisted Dehydration Process Applied to Red Globe Grapes for Producing Low Calorie Raisins
}

\author{
M. B. Laborde ${ }^{1,2,3}$, G. P. Barreto ${ }^{1,3}$, A. M. Pagano ${ }^{2,3, *}$ \\ ${ }^{1}$ Consejo Nacional de Investigaciones Científicas y Técnicas (CONICET), Buenos Aires, Argentina \\ ${ }^{2}$ TECSE - Departamento de Ingeniería Química y Tecnología de los Alimentos, Facultad de Ingeniería, \\ Universidad Nacional del Centro de la Provincia de Buenos Aires (UNICEN), Olavarría, Argentina \\ ${ }^{3}$ Departamento de Ingeniería Química y Tecnología de los Alimentos, Facultad de Ingeniería, Universidad Nacional del Centro de la \\ Provincia de Buenos Aires (UNICEN), Olavarría, Argentina \\ *Corresponding author: anamariapagano@gmail.com
}

\begin{abstract}
In this paper the application of ultrasound was investigated as a method for improving mass transfer during the first stage of a process of osmosis combined with dehydration drying to obtain grapes reduced in high calorie sugars. Fresh grapes (Vitis vinifera L.) Red Globe variety were subjected to immersion in distilled water at room temperature with assistance ultrasound $(40 \mathrm{kHz})$ using a weight ratio fruit: solvent of 1: 4, during regularly spaced intervals in the range 0-30 minutes; comparatively a control treatment without application of ultrasound (0 $\mathrm{kHz}$ ) was conducted. Subsequently, the grapes were stabilized by drying at $70^{\circ} \mathrm{C}$. The analysis of variance showed significant influence of treatment on the soluble solids content and gain at all times. The greatest sugars reductions were achieved when ultrasound was used. Process monitoring was conducted by assessing the change in the sugar content of grapes by refractometry ( $\left.{ }^{\circ} \mathrm{Brix}\right)$, and confirming the results by HPLC. The best treatment that significantly reduced $(p<0.05)$ the content of the major sugars in fresh fruit $(30 \%$ fructose and $27 \%$ glucose $)$ turned out to be 25 minutes immersion assisted by ultrasound.
\end{abstract}

Keywords: grapes, dehydration, ultrasound assistance, low calorie, raisins

Cite This Article: M. B. Laborde, G. P. Barreto, and A. M. Pagano, "Ultrasound-assisted Dehydration Process Applied to Red Globe Grapes for Producing Low Calorie Raisins." American Journal of Food Science and Technology, vol. 6, no. 5 (2018): 209-214. doi: 10.12691/ajfst-6-5-3.

\section{Introduction}

The Department of Productive and Technological Development of the National University of Lanús, Argentina (Co-Director Lic. Mariana Ugarte, Ing. José María Aulicino and Ing. Juan Manuel Alderete), determined, through quantitative research, that 9 out of 10 people incorporate sweets in their daily diet, cookies being top of the list, and breakfast, the time of day of greatest consumption. This food, usually consumed by adults through a peck for those moments of energy intake or pleasure, offers the practicality to be taken to work.

Argentine people consume, on average, three times more added sugar in sweet foods than the World Health Organization (WHO) recommends, whether through the consumption of soft drinks, processed foods, sweets or by sweetening infusions. The consumption of sugar should not exceed $10 \%$ of the total energy consumed in one day per person (equivalent to $50 \mathrm{~g}$ or 12 teaspoons for an average diet of 2,000 calories).

Excessive consumption of sugar over the years threatens health by favoring the development of dental caries, increased demand for B vitamins, hypertriglyceridemia, obesity and diabetes mellitus, among other complications [1]. It is possible to reduce the intake of sugar, incorporating into the diet, or prioritizing, the consumption of healthy foods (fruit, vegetables, dried fruits, seeds, yogurt, etc.).

Bibliographical records [2,3-9] show that it is possible to reduce the content of the sugars proper to fruits through osmotic dehydration with the application of ultrasound. The treatment consists in immersing the fruit in a hypertonic aqueous solution to which ultrasonic waves are applied. The advantage of using ultrasound is that the process can be carried out at room temperature and heating is not required, reducing the likelihood of food degradation [10].

Attending to this problem, and based on the results reported by researchers in different fruits, banana [2], melon [3], pineapple [4], papaya [5] and kiwi [9], the present work provides a healthy and less caloric alternative, to replace the most consumed sweet food in Argentina: cookies. The substituent that is proposed is a grape snack obtained from the transformation of a fruit rich in caloric sugars (mainly glucose and fructose) [11] into a natural product with a low caloric content, which can be consumed at different times of the day (breakfast and snacks) and in turn, it can be transported more easily and with less likelihood of decomposition than fresh fruit, yet providing the benefits of the latter.

The grape (Vitis vinifera L.) is the fruit of the vine that grows forming clusters. Although the final chemical composition of the grape varies depending on the genotype 
of the variety, environmental conditions, that is to say, soil, climate, crop management, etc. and the interaction between these factors [12], in general, it is rich in water and sugars. It also contains vitamins, minerals and other healthy compounds, such as polyphenols, with powerful antioxidant action, which make it very beneficial for the consumer. Some of the phenolic compounds that are native to the fruit are flavonols, quercetin and kaempferol, and phenolic, caftaric and coutaric acids, along with some other products that are formed during processing. Polyphenols provide health benefits, since they have a preventive effect against cardiovascular diseases and strokes [13], improve nutritional behaviors in patients with type II diabetes [14], and have the capacity to inhibit the proliferation of a wide variety of tumor cells (colon, breast, kidney and thyroid) $[15,16]$.

\section{Materials and Methods}

\subsection{Materials}

The tests were carried out from the pink grape (Vitis vinifera L.) of the Red Globe variety selected by size, color and ripeness state, acquired in the Central Tandil market (Province of Buenos Aires, Argentina) and stored in refrigeration $\left(2-5^{\circ} \mathrm{C}\right)$ until the moment of processing.

\subsection{Experimental Design}

To obtain raisins with low caloric content by osmotic dehydration, based on the removal of the main sugars in the fruit, glucose and fructose, a factorial experimental design was proposed, considering the following factors and levels:

- Type of treatment: with ultrasound $(40 \mathrm{kHz})$ and without ultrasound $(0 \mathrm{kHz})$,

- Time of osmosis: regular intervals in the range 0-30 minutes (initially set in 0, 10, 20 and 30 minutes),

with three repetitions, finishing the process with drying by hot air at $70^{\circ} \mathrm{C}$ until reaching a final humidity of the product of less than $18 \%$ w.b. (wet basis) [17].

\subsection{Experimental Procedure}

\subsubsection{Characterization of the Fruit}

The samples were characterized in terms of their average weight with / without seed (METTLER AE240 analytical scales, accuracy $\pm 0.0001 \mathrm{~g}$ ), characteristic lengths (manual gauge, accuracy $\pm 0.01 \mathrm{~mm}$ ), moisture content [18], content of soluble solids (ABBE refractometer, Japan, accuracy $\pm 0.05^{\circ}$ Brix), composition of main sugars (HPLC).

\subsubsection{Preparation of Samples and Experimental Proceeding}

Samples of fresh grapes were washed by immersion with potable water at room temperature for 10 minutes (in order to remove superficial waxes) and then drained. Next, as the first phase of a combined process of dehydration based on osmosis and drying by hot air to obtain low-calorie raisins, the fruits were subjected to an immersion treatment in aqueous solution assisted by ultrasound for the removal of the natural sugars of the grape. Finally, the samples with removed sugars were taken to a drying stage by hot air at $70{ }^{\circ} \mathrm{C}$ to stabilize the products.

In the osmosis stage, the samples were immersed in distilled water at room temperature, using a fruit: solvent ratio of 1: 4 by weight at the process times of 10 , 20 and 30 minutes, with the application of ultrasound. Comparatively, a conventional treatment was conducted without the application of ultrasound. All the tests were performed in triplicate. The samples that were exposed to ultrasound were treated at a frequency of $40 \mathrm{kHz}$. At the pre-set times, the samples were extracted from the solution, drained, placed on absorbent paper, and evaluated by weight (W), moisture content (M), soluble solids content (SS) and composition of main sugars.

As a final stage for the stabilization of the products reduced in caloric sugars, hot air drying was used in a forced draft oven, at a temperature of $70 \pm 1^{\circ} \mathrm{C}$.

\subsubsection{Determination of the Content of Soluble Solids}

The content of soluble solids (expressed as ${ }^{\circ}$ Brix) was measured by ATAGO refractometer, Japan (accuracy \pm 0.05 ) from the juice of the grape obtained by processing [19].

\subsubsection{Determination of Moisture Content}

The moisture content was determined by means of the forced convection oven drying method at $70 \pm 1{ }^{\circ} \mathrm{C}$, up to constant weight, on a $5 \mathrm{~g}$ sample, in triplicate (adaptation of Method 934.06 [18]).

\subsubsection{Determination of the Content of Main Sugars}

The identification and quantification of the main sugars of the grapes (glucose, fructose) was done by high precision liquid chromatography (HPLC) using a DIONEX UltiMate 3000 German UHPLC chromatograph equipped with an LPG-3400SD pump and RI Refractive Index detector 101A Phenomenex Luna-5- $\mathrm{NH}_{2}$ column $(250 \times 4.6 \mathrm{~mm})$ was used as the stationary phase. The mobile phase was used under isocratic conditions with a flow rate of $1 \mathrm{~mL} / \mathrm{min}$, composed of $\mathrm{CH}_{3} \mathrm{CN}-\mathrm{H}_{2} \mathrm{O}$ in proportion $65: 35(\mathrm{v} / \mathrm{v})$. The injection loop was $20 \mu \mathrm{L}$.

For this determination, extracts obtained by an adaptation of the method described by [20] were used. This process consisted in mixing $10 \mathrm{~g}$ of grapes cut into small pieces with $25 \mathrm{~mL}$ of $95 \%$ cold ethanol, which were exposed to an ultrasonic bath for $5 \mathrm{~min}$. The sample was spin-dried at $5000 \mathrm{rpm}$ for $20 \mathrm{~min}$ and filtered through 28 $\mu \mathrm{m}$ paper. The extract was collected and the process was repeated once again. The final extract was taken to $50 \mathrm{~mL}$ of final volume. Before proceeding with the HPLC injection, an aliquot with $0.45 \mu \mathrm{L}$ filter was filtered.

\subsection{Statistical Analysis of Results}

The results obtained were analyzed by means of ANOVA (analysis of variance) using the SYSTAT v12 software, in order to evaluate the influence of the immersion treatment time and the frequency of ultrasound applied on the caloric sugar content (fructose and glucose). 
This analysis included the following parameters: coefficient of determination $\mathrm{R}^{2}$, Student test $(\mathrm{t})$, Fisher test $(\mathrm{F})$ and $\mathrm{p}$-value. The statistical significance test level was set at 5\% (Probability, $\mathrm{p}<0.05$ ).

\section{Results and Discussion}

\subsection{Characterization of the Raw Material}

Table 1 shows some of the characteristics of the fresh grapes used in the treatments.

Table 1. Characterization of the raw material.

\begin{tabular}{|c|c|c|c|}
\hline \multirow{2}{*}{$\begin{array}{c}\text { Moisture content } \\
(\% \text { w.b. })\end{array}$} & \multirow{2}{*}{$\begin{array}{c}\text { Soluble solids content } \\
\left({ }^{\circ} \text { Brix }\right)\end{array}$} & \multicolumn{2}{|c|}{ Main sugars (mg/g) } \\
\cline { 3 - 4 } & Glucose & Fructose \\
\hline $81.80 \pm 0.85$ & $16.32 \pm 0.24$ & $34.12 \pm 4.44$ & $40.44 \pm 4.11$ \\
\hline
\end{tabular}

\subsection{Analysis of the Process}

In all experiments, the moisture contents of samples increased between 2.9 and $7.6 \%$ with respect to the initial moisture content of fresh fruit. Highest moisture content was obtained when ultrasound was applied during 30 minutes, as shown in Figure 1a. In the same order, Reference [2] reported small changes of moisture content in banana cylinders (increasing of about 5.5\%) at the end of the ultrasonic treatment of 30 minutes.

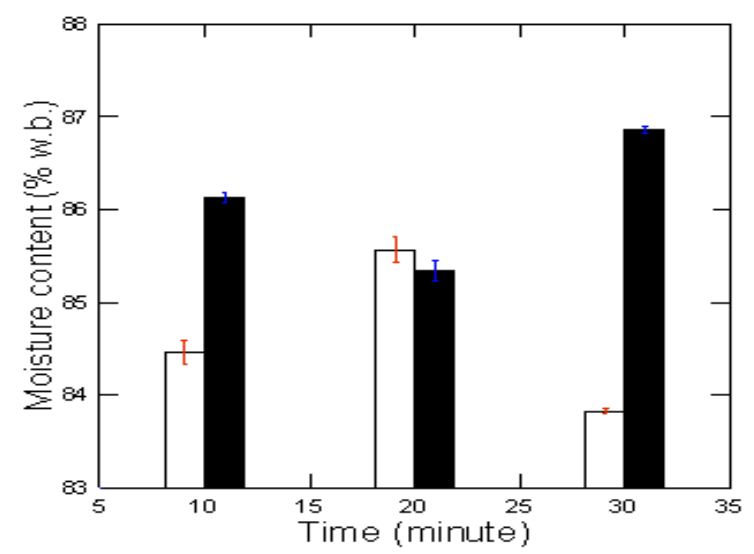

(a)

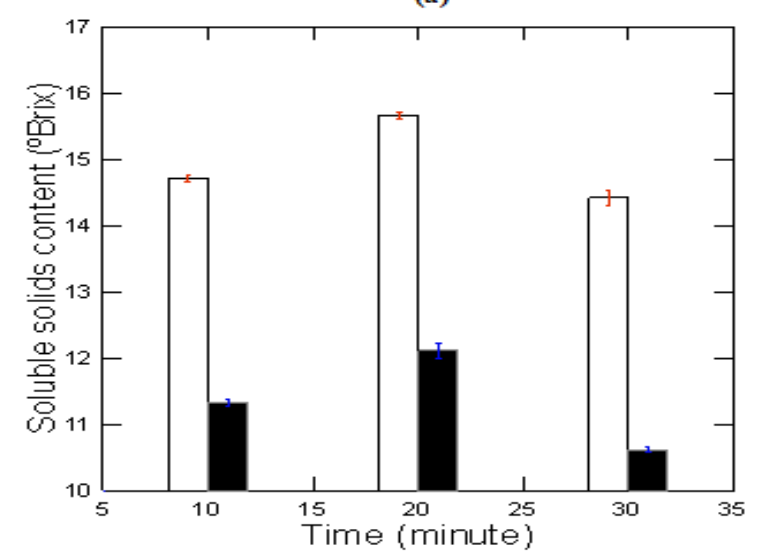

(b)

Figure 1. Moisture content (a) and soluble solids content (b) of grapes samples during the stage of the removal of sugars from the fruit by immersion in distilled water without and with ultrasound application ( $\square$ noUS, $\square$ US)
The analysis of the variance (ANOVA) showed a significant effect of the type of treatment $(p<0.03)$ on the moisture content of the samples. However not influence of the immersion time or of the interaction between the experimental factors were observed.

The results of the soluble solids content of the samples subjected to the stage of elimination of the sugars characteristic of the fruit are presented in Figure $1 b$, expressed in ${ }^{\circ}$ Brix at different times of immersion in distilled water with and without the application of ultrasound (US and noUS, respectively).

Different values were obtained for the soluble solids content of the samples processed, due to both the effect of different immersion times and the type of treatment applied. Comparatively, it was observed that the use of ultrasonic waves in the osmosis significantly facilitated the removal of more soluble solids from the samples than the treatment without ultrasound assistance, for all the process times considered $(\mathrm{p}<0.00002)$. No effect of time and of the interaction between time and treatment type was observed. This behavior of loss of soluble solids in the process was similar to that reported by other authors in other working matrixes such as banana, melon, pineapple and strawberries $[2,3,4,7]$.

The highest relative percentage elimination of the fruit's own sugars (34\%), expressed as soluble solids content, was present in the ultrasound-assisted treatment for an immersion time of 30 minutes, reaching a final content of soluble solids of $10.69 \pm 0.065^{\circ}$ Brix. On the other hand, by means of the conventional treatment without application of US, only the original sugars of the fruit were reduced to a final content of $14.42 \pm 1.50{ }^{\circ}$ Brix, representing a loss of only $12 \%$ of the fresh fruit. Anyway, in all the cases the soluble solids content of the treated samples was significantly lower than the corresponding to the non-treated grapes. Therefore, the use of ultrasound in the treatment appears such as more advantageous for the reduction of sugars.

But, considering that the immersion process involves a double contrasting flow of matter (where the soluble solids go from the interior of the fruit to the solvent medium that surrounds it, while the water goes from the surrounding liquid medium to the interior or the vegetable), is proper to use normalized percent variables such as weight reduction (WR) (Eq. 1), water loss (WL) (Eq 2) and soluble solids gain (SG) (Eq. 3) to describe the treatment.

$$
\begin{gathered}
W R(\%)=\left(\frac{W_{0}-W}{W_{0}}\right) 100 \\
W L(\%)=\left[\left(1-\frac{T S_{0}}{100}\right)-\left(1-\frac{T S}{100}\right)\left(1-\frac{W R}{100}\right)\right] 100 \\
S G(\%)=\left[\left(1-\frac{W R}{100}\right) \frac{T S}{100}-\frac{T S_{0}}{100}\right] 100
\end{gathered}
$$

where: $\mathrm{W}_{0}$ is the mass $(\mathrm{g})$ of the fresh fruit sample; $\mathrm{W}$ is the mass $(\mathrm{g})$ of the sample at each time of treatment; $\mathrm{TS}_{0}$ is the total solids content $(\%)$ of the fresh fruit sample; TS is the total solids content $(\%)$ of the sample at each time of treatment.

When analyzing these normalized variables by ANOVA, it was demonstrated that the treatment type had significant 
effect on WR $(p<0.00008)$, without influence of the time of immersion of the interaction between the parameters time and treatment. For each subgroup of treatment (without ultrasound and with ultrasound), the time was not significant on the weight reduction. Clearly higher values of WR were observed for the treatment assisted by ultrasound (Figure 2a).

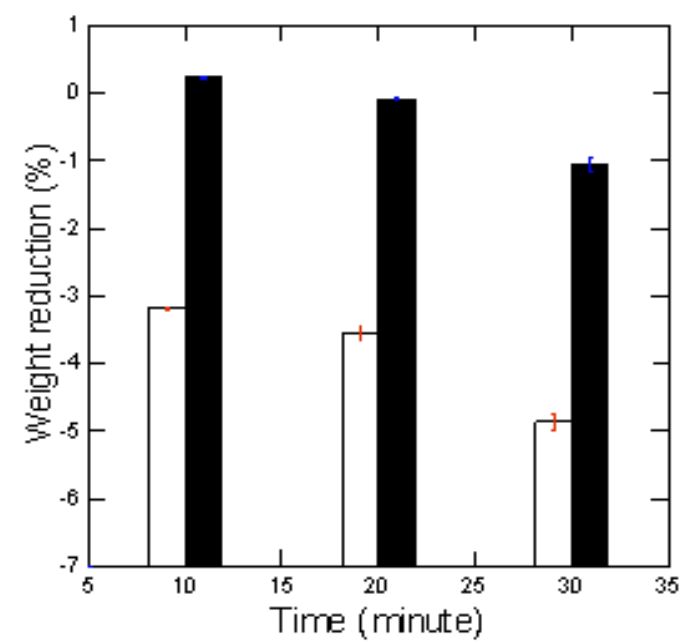

(a)

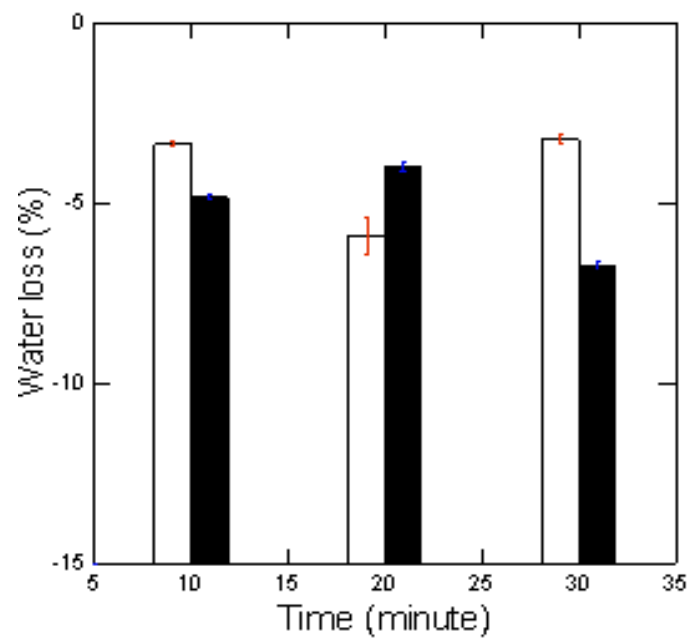

(b)

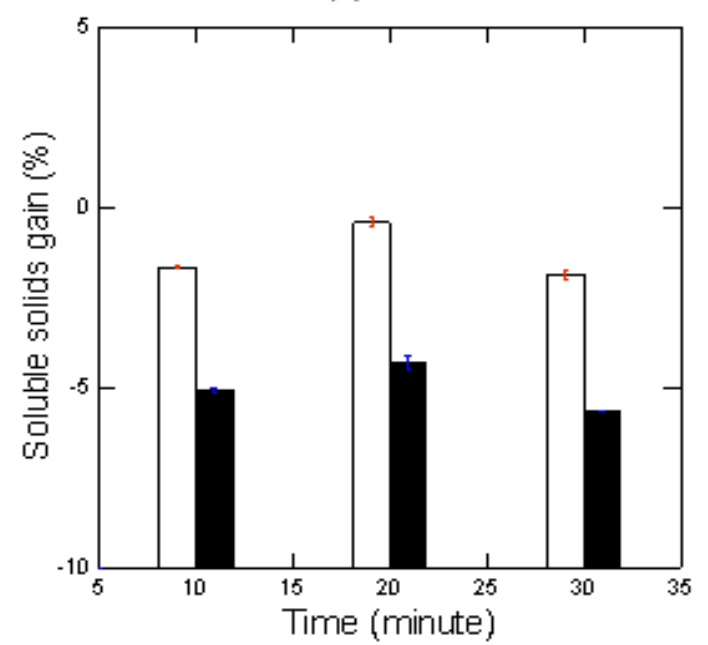

(c)

Figure 2. Weight reduction (a), water loss (b) and soluble solids gain (c) of grapes samples during the stage of the removal of sugars from the fruit by immersion in distilled water without and with ultrasound application ( $\square$ noUS, $\square$ US)
Weight reduction (WR) responding to a reduction of water content is important in the dehydration, because it is directly associated with reduction of time or cost of the process to reach the final product. Then, the variables weight reduction, water loss and soluble solids gain must be jointly analyzed in order to determine the optimum levels of the process parameters for the objective of reduce the sugars of grapes samples.

Water loss (WL) varied between -14.35 and $-1.48 \%$ during the treatment without and with assistance of ultrasound (Figure 2b). But, no effect of the type of treatment on WL was detected from the analysis of the variance. Neither the immersion time, nor the interaction between time and treatment type were significant.

On the other hand, the gain of soluble solids (SG) was significantly affected by the treatment type $(p<0.0002)$, as can be seen in Figure 2c. This standardized variable did not have a significant effect of the time of immersion nor of the interaction between the immersion time and the ultrasonic treatment. In each treatment (US or noUS), no significant differences between the consecutive immersion times were found, regarding the soluble solids gain of the samples; but the differences between SG values of the treated samples with respect to the fresh fruit were were noteworthy $(\mathrm{p}<0.05)$ in all the experiments.

Ultrasound assistance clearly favored the reduction of the soluble solids of the grapes samples at all immersion times; as Figure 2c shows, the values of SG were significantly lower than the treatment without ultrasound, principally at the highest time of process. The same conclusion was previously highlighted for the variable denoted as content of soluble solids, evidencing a behavior consistent with SG that responded to a linear relationships between these variables, as can be noted in Figure 3 for US $\left(\mathrm{R}^{2}=0.99\right)$.

\section{Confidence Interval and Prediction Interval}

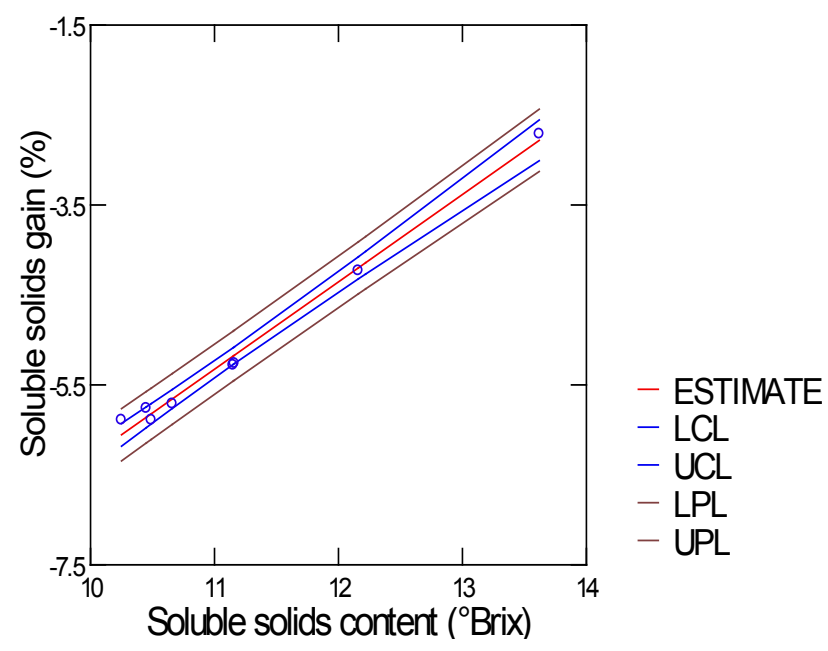

Figure 3. Linear correlation between the soluble solids content and the soluble solids gain of grapes samples during the stage of the removal of sugars from the fruit by immersion in distilled water with ultrasound application

With the aim to obtain the optimum conditions to reach the highest sugar reduction of the grapes samples, the methodology of response surface was applied to the data set of ultrasound treatment. Both variables, soluble solids 
gain (SG) and soluble solids content were acceptably described by second order polynomials depending on the immersion time $\left(R^{2}=0.78\right.$ and $R^{2}=0.75$, respectively). From the analysis of ridges, the optimum time for minimize the soluble solids gain $(-5.32 \%)$ was 30 minutes, while the optimum time for the minimum soluble solids content $\left(10.73^{\circ}\right.$ Brix $)$ resulted 24 minutes.

In order to corroborate the sugar elimination behavior in the samples with greater degree of detail, the qualitative and quantitative determination of the main sugars of the grape (fructose and glucose) was carried out by means of HPLC at different stages of the US treatment. New additional intervals of evaluation at intermediate times (5, 15 and 25 minutes) were included. The results are presented in Figure 4.

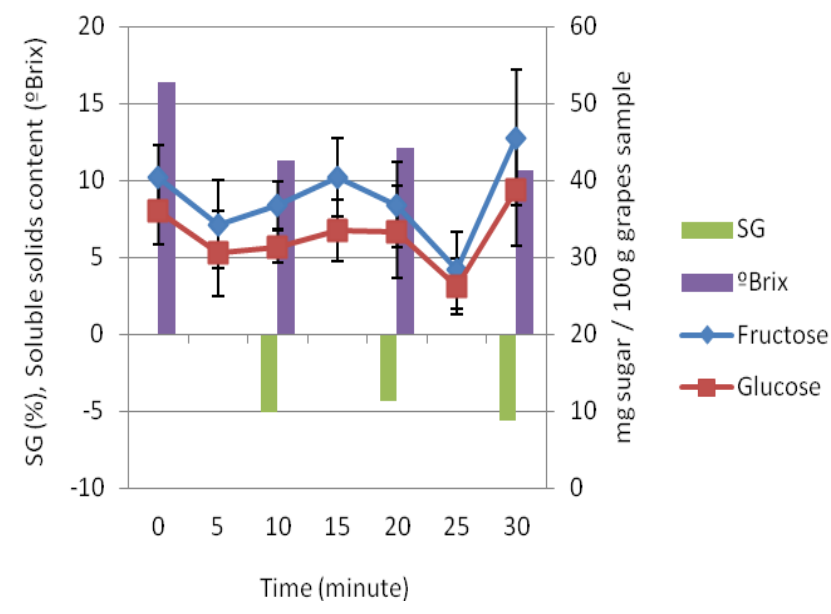

Figure 4. Temporal behavior of the main sugars of grapes (fructose and glucose) compared with the control variables soluble solids gain (SG) and soluble solids content (SS) during the stage of the removal of sugars from the fruit by immersion in distilled water with ultrasound application

As seen in Figure 4, the fresh grape presented a higher content of Fructose than Glucose, and, although the content of the main sugars was varying in the samples throughout the treatment, the mass ratio between both carbohydrates $\left(\mathrm{R}^{2}=0.95\right)$ remained practically constant $(1.140 \pm 0.045 \mathrm{mg}$ Fructose / mg Glucose)

With the aim of analyzing the influence of the process time on the removal of sugars, a statistical analysis of the variance of the Fructose and Glucose content of the samples treated during the process was carried out. As a result, significant differences $(p<0.05)$ were found between the carbohydrate content of the fresh fruit $(t=0)$ and that of the samples at a final time of 25 minutes' immersion in distilled water with ultrasound application, both in the case of Glucose $(p=0.041)$ and in Fructose $(\mathrm{p}=0.032)$.

In Figure 4 it can be noted that, under these conditions, it was possible to remove the greatest proportion of the main sugars present in the fresh grape, representing this reduction $30 \%$ of Fructose and $27 \%$ of Glucose. Therefore, a process time of 25 minutes of osmosis assisted by ultrasound is selected as the best treatment to reduce the content of the main sugars of the grapes. As was expected, this optimum time to obtain the better reduction to grapes sugars resulted intermediate between the optimum previously predicted for the variables SG and SS.
The comparative advantage of using this US technology as a method to improve mass transfer during osmosis could be attributed to the effect of the ultrasonic waves when they pass through the fruit matrix, inducing compression and expansion of the material, causing the so-called "sponge effect" [21,22]. This phenomenon leads to the formation of micro channels in the cell structure, which leads to facilitate the loss of soluble solids from the intracellular region to the core.

Considering that in raisins the greatest contribution of calories comes from carbohydrates and that each gram of this macronutrient contributes $4 \mathrm{kcal}$, through the selected treatment a reduction of $8.8 \mathrm{kcal}$ per $100 \mathrm{~g}$ of raisins was obtained, representing a significant change $(\alpha=0.05)$ in energy content between fresh grapes and raisins reduced in calories. The obtained result allows revalidating that the treatment with ultrasound guarantees a final product with low caloric content since it decreases by $28.73 \%$, taking into account only the contribution of the sugars. The fresh grape contributes $30.63 \mathrm{kcal} / 100 \mathrm{~g}$ whereas the raisin reduced in calories contributes $21.83 \mathrm{kcal} / 100 \mathrm{~g}$.

\section{Conclusions}

The application of ultrasound was investigated as a method to improve the mass transfer in the stage of removal of the caloric sugars of the grape by osmosis, as part of the combined dehydration process for obtaining raisins reduced in calories.

As a result of the study, it is concluded that it is possible to reduce a $28.7 \%$ of the main carbohydrates of the grape (fructose and glucose) by immersing the fresh fruit in distilled water at room temperature with the assistance of ultrasound $(40 \mathrm{kHz})$, using a ratio in fruit weight: solvent of 1: 4 for 25 minutes.

By means of the selected treatment, a significant reduction is achieved in the energy value of the fresh grape of $8.8 \mathrm{kcal}$ per $100 \mathrm{~g}$ of raisins.

\section{Acknowledgements}

The authors thank the Secretaría de Arte, Ciencia y Tecnología (SECAT) of UNICEN, the Secretaría de Políticas Universitarias (SPU) of the Ministerio de Educación de la Nación Argentina, and the Consejo Nacional de Investigaciones Científicas y Técnicas (CONICET) for the financing granted to the project and the doctoral fellowship of Lic. M.B. Laborde.

\section{References}

[1] Blanco Anesto, J., "Consumir azúcar con moderación," Revista Cubana Alimentación y Nutrición, 16 (2). 142-145. 2002.

[2] Fernandes, F.A.N. and Rodrigues, S., "Ultrasound as pretreatment for drying of fruits: Dehydration of banana," Journal of Food Engineering, 82 (2). 261-267. 2007.

[3] Fernandes, F.A.N., Gallão, M.I. and Rodrigues, S., "Effect of osmotic dehydration and ultrasound pre-treatment on cell structure: Melon dehydration," Food Science and Technology, 41 (4). 604-610. 2008a. 
[4] Fernandes, F.A.N., Linhares, F.E. and Rodrigues, S., "Ultrasound as pretreatment for drying of pineapples," Ultrasonics Sonochemistry, 15 (6). 1049-1054. 2008b.

[5] Fernandes, F.A.N., Oliveira, F.I.P. and Rodrigues, S., "Use of ultrasound for dehydration of papayas," Food Bioprocess Technology, 1. 339-345. 2008c

[6] Rodrigues, S. and Fernandes, F.A.N., Ultrasound in fruit processing. In: New Food Engineering Research Trends. Editor: Alan P. Urwaye. pp. 103-135. ISBN: 978-1-60021-897-2. 2008.

[7] García-Noguera, J., Weller, C.L., Oliveira, F.I.P., Rodrigues, S. and Fernandes, F.A.N., "Dual-stage sugar substitution in strawberries with a Stevia-based sweetener," Innovative Food Science and Emerging Technologies, 11 (1). 225-230. 2010.

[8] Oliveira, F.I.P., Rodrigues, S. and Fernandes, F.A.N., "Production of low calorie Malay apples by dual stage sugar substitution with Stevia-based sweetener," Food and Bioproducts Processing, 90 (4). 713-718. 2012

[9] Nowacka, M., Tylewicz, U., Laghi, L., Dalla Rosa, M. and Witrowa-Rajchert, D., "Effect of ultrasound treatment on the water state in kiwifruit during osmotic dehydration," Food Chemistry, 144. 18-25. 2014.

[10] Mason, T.J., "Power ultrasound in food processing - the way forward". En: M. J. W. Povey y T. J. Mason (Eds.), Ultrasounds in food processing (pp. 105-125). Glasgow: Blackie Academic and Professional. 1998.

[11] Eyéghé-Bickong, H.A., Alexandersson, E.O., Gouws, L.M., Young, P.R. and Vivier, M.A., "Optimisation of an HPLC method for the simultaneous quantification of the major sugars and organic acids in grapevine berries," Journal of Chromatography B, 885-886. 43-49. 2012.

[12] Carbonell Bejerano, P. and Martínez Zapater, J.M., "Estructura y composición de la uva y su contribución al vino," Acenología. Revista de Enología Científica y Profesional, 139. 2013.

[13] Williamson, G. and Carughi, A., "Polyphenol content and health benefits of raisins," Nutrition Research, 30 (8). 511-519. 2010.
[14] Kanellos, P.T., Kaliora, A.C., Tentolouris, N.K., Argiana, V., Perrea, D., Kalogeropoulos, N., Kountouri, A.M. and Karathanos, V.T., "A pilot, randomized controlled trial to examine the health outcomes of raisin consumption in patients with diabetes, Nutrition, 30 (3). 358-364. 2014.

[15] Sun, T., Chen, Q.Y., Wu, L.J., Yao, X.M. and Sun, X.J., "Antitumor and anti metastatic activities of grape skin polyphenols in a murine model of breast cancer," Food and Chemical Toxicology, 50 (10). 3462-3467. 2012.

[16] Sahpazidoua, D., Geromichalosa, G.D., Stagos, D., Apostolouc, A., Haroutounianc, S.A., Tsatsakisd, A.M., Tzanakakise, G.N., Hayesf, A.W. and Kouretas, D., "Anticarcinogenic activity of polyphenolic extracts from grape stems against breast, colon, renal and thyroid cancer cells," Toxicology Letters, 230 (2). 218-224. 2014.

[17] Codex Alimentarius. CODEX STAN 67-1981.

[18] AOAC. (1990). Association of Official Agricultural Chemists. Método 934.06.

[19] Nordey, T., Léchaudel, M., Génard, M. and Joas, J., "Spatial and temporal variations in mango colour, acidity, and sweetness in relation to temperature and ethylene gradients within the fruit," Journal of Plant Physiology, 171 (17). 1555-1563. 2014.

[20] Muñoz-Robredo, P., Robledo, P., Manríquez, D., Molina, R. and Defilippi, B.G., "Characterization of sugars and organic acids in commercial varieties of table grapes," Chilean Journal of Agricultural Research, 71 (3). 452-458. 2011.

[21] Nowacka, M., Wiktor, A., Sledz, M., Jurek, N. and WitrowaRajchert, D., "Drying of ultrasound pretreated apple and its selected physical properties," Journal of Food Engineering, 113 (3). 427-433. 2012.

[22] Laborde, M.B., Barreto, G.P. and Pagano, A.M., "Pasas de uva de bajas calorías obtenidas por deshidratación combinada: optimización del proceso y evaluación de la eficiencia antioxidante," Avances en Ciencias e Ingeniería, 6 (1). 17-30. 2015 . 